Sultan Qaboos University Journal of Arts \& Social Sciences
جامعة السلطان قابوس الإسلوداب

مجلة الآداب والعلوم الاجتمانعية

\title{
The Right to Know and Freedom of Expression in the Arab World in the Digital Age
}

\footnotetext{
Iman Mohamed Mohamed Zahra

Assistant Professor

Department of Mass Communication

Sultan Qaboos University

imanz@squ.edu.om
}

\begin{tabular}{c}
\hline Hosni Mohamed Nasr \\
\hline Professor \\
Department of Mass Communication \\
Sultan Qaboos University \\
hosnin@squ.edu.om
\end{tabular}

hosnin@squ.edu.om 


\title{
The Right to Know and Freedom of Expression in the Arab world in the Digital Age
}

\author{
Iman Mohamed Mohamed Zahra and Hosni Mohamed Nasr
}

\section{Abstract:}

'The right to know' represents a fundamental and vital human right. Progress and development of nations fully require information freedom and knowledge sharing. Using a qualitative analysis of a sample of information and press laws in most Arab states, this paper aims at discussing 'the right to know' from different perspectives while highlighting the surrounding aspects and their consequences on the right of freedom of expression in those states. The paper also tends to clarify the effects of new media on the vision and practices of governments regarding 'the right to know' and the freedom of the press in the digital age. Moreover, the paper analyzes the different types of censorship the Arab states use to control the new media. Findings shed light on different aspects of 'the right to know' within the different challenges of the digital age and clarify the strong bondage of this right with the other human rights, especially freedom of expression and freedom of the press.

Keywords: Digital Age; Freedom of expression; Freedom of the press; Publication laws; Right to know.

\section{الحق في المعرفة وحرية التعبير في العالم العربي في العصر الرقمي}

\author{
إيمان محمد زهرة وحسني محمد نصر
}

يمثل الحق في المعرفة حقاً إنسانياً أساسياً وحيوياً، إذ يتطلب تقدم الأمهم وتطورها إقرار وضمان حرية تداول المعلومات وتشارك المعرفة.

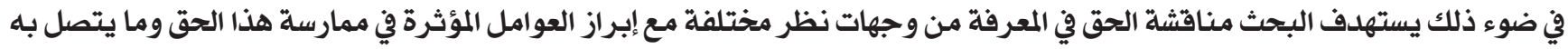
من حقوق أخرى مثل حرية التعبير، في الدول العربية محل الدراسة، وذلك من خلال استخدام التحليل الكيفي لعينة من قوانين الصحافة

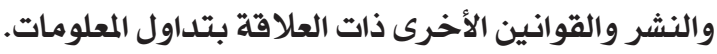
ويسعي البحث أيضا إلى كشف وتحليل أثر وسائل الإعلام الجديلدة على رؤى وممارسات الحكومات العربية فيما يتعلق بالحق في المعرفة وحرية الصحافة في العصر الرقمي. ويناقش البحث أنواع الرقابة المختلفة التي تستخدمها الدول العربية للسيطرة على منصات الإعلام

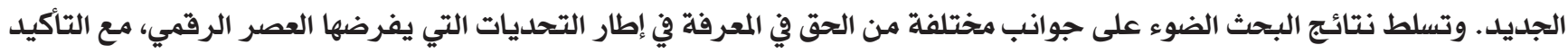
على العلاقة الوثيقة بين الحق في المعرفة وبين حقوق الإنسان الأخرى، وبصفة خاصة حرية التعبير وحرية الصحافة الصفة

$$
\text { الكلمات المفتاحية: الحق في المعرفة؛ حرية التعبير؛ حرية الصحافة؛ قوانين المطبوعات؛ العصر الرقمي. }
$$


Introduction:

The right to know represents a fundamental and vital human right that cannot be abandoned. It is a major demand for any country trying to establish a real democracy and combat corruption. This right is the base of all freedom aspects and is defined as: the right of every individual to know and have access to information he needs to establish his free choices and practice his life independently (UN General Assembly, 1946). Boserup $(2005,5)$ asserts that the right to know guarantees access to information through executed procedures to make ruling authorities more visible by the society, thus boosting mass trust of the given authorities. These procedures include: easy access to information owned by governmental institutions and public right to attend hearing sessions and open meetings.

The right to access and disseminate information is considered one of the most apparent enhancing mechanisms of practicing other human rights. This right tends to be a major factor in preparing a general context that respects, protects and fulfils other rights, whether on an individual or societal level.

In the book "The Right to Know ... The Right to Live,» Jagwanth (2002) attributed the relationship between the right to know and other rights to being a part and a fundamental component of practicing other rights such as freedom of expression, the right to fair trials, etc. Moreover, the right to know protects and boosts other rights such as social and economic rights, supports the defense of the right to exercise other rights, or prevents further violations of other rights by providing objective and organized surveillance and accountability. (Access to information, 2007; Jagwanth, 2002: 7).

The current research paper aims at analyzing the right to know in the Arab World and its reflections on the freedom of expression - especially in the context of evolving new media - from different angles; through concentrating on the vision and practices of governments regarding the right to know and freedom of the press in the digital age. The study speculates that problems related to the right to know are not caused by the authoritarian Arab Regimes so much as by the public unawareness of this right and methods of its practice.

Through the qualitative analysis of media and press laws and Arab practices in the field of freedom of knowledge, findings shed light on different aspects of the right to know within the different challenges of the digital age. The strong bondage of this right with the other human rights especially freedom of expression and freedom of the press is clarified. Moreover, the paper tackles aspects of importance of the right to know in different Arab States and analyzes specific case studies where the right to know overlaps with the freedom of the press and freedom of journalists.

\section{Methodology and Literature Review:}

Research Problem

Arab countries have not been late in catching up with the digital communications revolution that entered the public domain in the early 1990s. By the end of the 1990s, all Arab countries had entered the digital age, especially regarding the internet and web usage as a new mass communication medium.

Arab entry into the digital age and the availability of its technologies and tools to the public have caused many concerns among regimes of different ideologies. These concerns focused on consequences of the widespread use of the internet on destabilizing these regimes and breaking the control exercised on the traditional media for many years. Relying on this perspective, the majority of Arab countries hastily imposed restrictions on this use, including economic, legislative and legal restrictions; in addition to controlling the content published on websites using classification and filtering technologies; not to mention their closure in some cases. In severe circumstances, some countries escalated to the level of cutting internet services for the whole country, as happened during the Egyptian uprising of January 25, 2011.

The interaction of the Arab regimes with the technologies of the digital age raises the question about the extent to which Arab countries are committed to the universal right to know and expressing opinions; established by international conventions and also, by Arab constitutions. In light of the previous argument, the current research intends to discuss and analyze the reality of the right to know and freedom of expression in the Arab world, through focusing on the existing dilemma between balancing the privileges offered to Arab citizens by digital communication technology and its great communication potential that allowed them to access all outlets of knowledge and freedom of expression; and between restrictions Arab governments are trying to impose to limit the right to know and freedom of expression for Arab citizens.

\section{Literature Review}

Literature review dwelt upon lots of issues related to the right to know and freedom of expression in many Arab countries, and sometimes extend internationally. In the upcoming review, the researchers will focus on international studies related to the issue in hand; then present studies that focused mainly on the rights in Arab countries. 
From an international perspective, and in looking for a universal declaration on digital (internet) rights and freedom, Pettrachin (2018) suggests that the formalization of the discourse on internet-related human rights might be carried out adopting a multi-level governance approach. The 'local-global connection,' is indeed crucial for the affirmation of norms on digital rights and it is still 'mainly within national contexts, that these norms actually take shape and gain recognition.' While many invoke some form of consensus around some general principles at the international level, in particular, two pieces of legislations containing bills of internet-related human rights at the national level have been recently approved (in Brazil and the Philippines). These and other initiatives and their implementation should be monitored and studied, since they crucially contribute not only to the evolution of the discourse on internetrelated human rights but also to its formalization into enforceable norms.

Abd Al Gawad (2003) pointed out that: with the development of societies due to the advancement of technology and the emergence of the so-called information revolution, lawmakers have raced against time to enact legislation that can control the continuous and successive changes in society. Some societies banned the new technology, others allowed usage of some new technology and some not. Western societies have tried to digest the information revolution and harness it for the benefit of society. The authoritarian regimes, though have tried to prevent people from accessing information technology and their spread in society, at times; and at others, those regimes specified features that can be used in society. The researcher asserted that the right to know means the right to access information sources and know what the government is doing.

In their analysis of the legislative history of how Congress established a right of public access to electronic information, Halstuk and Chamberlin $(2001,57)$ concluded that a slow response to bridging the gap between law and technology can restrict the right to know. For these reasons, the next big challenge that congress faces regarding freedom of information is to keep abreast of new developments in communication technology. Legislators, therefore, should get up to speed on where Internet technology is headed next, so they can harness new innovations to fortify and enhance the right to know.

Chalaby's study (2000) is considered the closest to the current research. It tackled the new freedoms created by the digital age, and the new threats it has raised to the situation in different countries. Chalaby analyzed censorship on traditional media outlets and compared them to the methods currently used in most countries with online journalism and online publishing in general. The study focused on the new pattern of censorship that has accompanied the advent and prosperity of the internet and was not previously known with traditional media, namely technological censorship, through classification and filtering programs. The study concluded that this new pattern is more dangerous than previous censorship patterns because it is invisible and may not be sensed by the user. The current research employs some of Chalabyss conclusions to describe the reality of exercising the right to know and freedom of expression in the Arab world in the digital age.

On the other hand, some studies provided important background on the constitutional and legislative reality that governs technologies of the digital age in a number of countries - not including Arab countries - which researchers refer to as some of the worldis most hostile towards the internet. These studies can be considered relevant to the topic of the current research; although they are not related directly to its objectives; since the research in hand focuses on the reality of the right to know and freedom of expression in the Arab world.

One of these studies is Ang's (1999) which analyzed the approaches used globally to regulate the use of the internet. He concluded that every country that regulates the use of the Internet is driven not only by technology and law, but mainly by the culture of society. Moreover, each country has specific concerns of the internet, which makes the internet legislation differ from country to another. Ang noted that most countries pose internet regulations under the regulation of broadcasting. He pointed out that despite increasing media laws in some countries, most countries are trying to make their censorship on the internet less severe; and although there are laws governing the internet in some countries, these laws are not strictly enforced. He added that governments ) belief that controlling the internet is difficult makes censorship imposed on it not intended to be fully implemented. Internet censorship is no more than a "political statement» to confirm the governmentss existence in this field. These results provided an opportunity to compare the constitutional and legal organization of the right to know and freedom of expression via digital media in the Arab countries to the global reality previously discussed by Ang.

Regarding research that focused on the Arab Countries, El-Sadany (2017) pointed out in a survey on human rights in Arab constitutions, that all the countries surveyed, issued constitutions which guarantee the freedoms of expression, opinion, and the press; 
however, some of the guarantees are conditional. In her research on the Twitter Revolution in the Gulf Countries, Al-Jenaibi (2016) asserted that the use of Twitter is shifting the Arab people's discourse and opinion in the Kingdom of Saudi Arabia, because those opinions are being heard instead of censored. She pointed out that the social media have a major impact on the conservative Saudi, Qatar and UAE societies.

Moreover, in his study on building the knowledge society - considering the right to access to information and challenges that the right to know is accompanied by the right to access information - Fadl Allah (2012) concluded that the number of countries with constitutions including the right to access information (is 93) only, and that all Arab countries have no legislation guaranteeing the right to access information except one at that time; despite some attempts in other countries. On this basis, a knowledge society cannot be built in the absence of the right to access information.

In their analysis of Internet political discussion in the Arab world, Al Nashmi et al. (2010) gave some examples that show how the Arab governments dealt with the digital age technologies and media. The Saudi government thought the internet might have a long-term impact on the stability in the region, so they took a more cautious approach before launching it. The government of Saudi Arabia is believed to have the strictest and most extensive internet censorship practices in the world. However, the Egyptian government has taken a relatively benevolent approach towards the internet, creating 'a censorship-free' system, still, the government has been able to crack down on people who posted controversial material online.

Nasr (2003: 246- 247) concluded that almost all governments in the world, including democratic governments, are trying to intervene to regulate the use of the internet for two key factors: to ensure that internet services within the country are not monopolized by one or a few companies, thus exploiting monopoly to censor the content of the network as was the case with other media outlets. The second factor is to ensure that what is published online is not of pornographic or political nature that the citizens should not be exposed to. The means of control imposed by some Arab governments on the internet include: controlling permits of the service providers in the country, extending publishing and broadcasting laws to include the internet and imposing direct control on the content of the network that is inclined to oppose the ruling system, traditions and country values.
On the same issue, Al Araby (2002: 22) mentioned the massive increase of internet subscription prices in Saudi Arabia, which was considered at the time the highest in the Gulf and five times the global price rate. These prices can be considered as economic restrictions on freedom of expression on the internet in the Arab world. In his research on freedom of expression and censorship in the new media, Al Laban (2002: 36- 37) asserted that most Arab countries consider themselves facing a threat from the internet and therefore, tend to censor and control access to the internet to disrupt destructive materials.

Regarding the control of the most prominent techniques of the digital age (the internet) in the Arab countries, Bukhart (1998), reached a number of approaches used by Arab governments to reduce the flow of information to their citizens over the internet and control them, namely: controlling the main telecommunication infrastructure in the countries, monopolizing internet services, using banning software as firewalls, surveillance servers as proxy servers and charging expensive prices for internet services.

The severity of internet censorship in the Middle East is due, from Rathmell's point of view (1997), to government's unwillingness to send information online to their citizens without censorship, while Shuji (1997), refers to continuous governmental fear regarding national security that escalated with the prevalence of internet.

Finally, some researchers including Ellickson (1991) adopted an approach called the Light-Handed Approach as the most appropriate approach for interpreting the degree of censorship imposed by most governments on the internet. The implication of this approach is that some governments do not hold internet service providers accountable for illegal or unethical materials posted online; and some attempts to regulate the internet have emerged from the desire to harmonize the laws governing the functioning of traditional and new media and remove the conflict between them.

Ellickson specified the countries that severely controlled the internet and its services and content in 1991 namely: Azerbaijan, Belarus, Burma, China, Cuba, Iran, Iraq (before US invasion), Kazakhstan, Libya, North Korea, Saudi Arabia, Sierra Leone, Sudan, Syria, Tajikistan, Tunisia, Turkmenistan, Uzbekistan and Vietnam. Ellicksonss list in 1991 included six Arab countries. Some of those countries witnessed a change in their political systems and some witnessed dramatic changes in the techniques and media of the digital age, thus adopting different approaches in dealing with the digital age and accompanying 
technologies.

Research Questions and methods

The research intends to answer four main questions as follows:

Question 1: What is the right to know and what is the effect of this right on other rights and freedoms?

To answer this question, the researchers resided to the secondary analysis of literature and academic papers that dealt with the definition of the right to know and its close association with other rights and freedoms such as freedom of expression and freedom of the press.

Question 2: What is the reality of the right to know in international covenants and its outcomes in Arab constitutions?

To answer this question, the researchers analyzed Resolution No. 59 adopted by the General Assembly during its first meeting in 1946, Article 19 of the Universal Declaration of Human Rights, Article 19 of the International Covenant on Civil and Political Rights and the International Covenant on Economic and Social Rights, in addition to the reports of the special rapporteur on Freedom of opinion and expression.

Moreover, the researchers analyzed a number of relevant Arab covenants including the Arab Charter on Human Rights adopted by the Council of the Arab League on September 15, 1997, as well as the constitutions of the Arab countries available on the web, which are 20 available at the Algerian Legal Library in the Encyclopedia of Arab Constitutions http://www.law-dz.net; in addition to the basic governing system in the Kingdom of Saudi Arabia, the Constitution of the Kingdom of Morocco issued in 2011, and the Constitution of the Republic of Iraq issued in 2005.

Question 3: What is the reality of practicing the right to know and freedom of information exchange in the Arab world?

To answer this question, the researchers applied the five principles elaborated by Article 19 on the Arab Countries, concerning the right to know and freedom of circulation of information. These principles are considered the basic criteria for judging the commitment of States to this right. Article 19 Organization is a non-governmental organization established in London in 1987 to monitor surveillance. The organization clarified a number of principles related to the right to know and freedom of circulation of information namely: the absolute disclosure of information, obligation to publish, promoting the concept of open government, limited scope of exceptions, as well as procedures to facilitate access to information.
Question 4: What is the impact of the digital age on the right to know and freedom of expression in the Arab world?

To answer this question, researchers analyzed the changes in the reality of exercising the right to know and freedom of expression in the Arab countries through the media openness generated by the digital age. The researchers tackled the reality of six practices that are still the subject of controversy on the Arab level: secrecy of information, public interest, gag orders, information classification, banning governmental employees from revealing information to the press, the right of media to attend public meetings and court hearings.

\section{Major Findings:}

Findings of the current study will be presented in the following sequence: effect of the right to know on other rights and freedoms; the right to know in Arab and International Charters; reality behind the principles of the right to know and freedom of the circulation of information in the Arab World; absence of the right to know in Arab World constitutions; absence of protective laws of the right to know in the Arab World and reflections of the right to know on freedom of information and freedom of the press. The paper is concluded with comments on the right to know in the Arab World in the digital age. Conclusions and recommendations follow.

\section{The Effect of the Right to Know on Other Rights} and Freedoms

The right to know represents a fundamental and practical mechanism to enhance the package of economic, social and cultural rights on one hand and as a major component of the civil and political rights package on the other hand.

There is a well-established relationship between the right to know and the dissemination of information and the governance of Arab societies. Respecting the right to know is considered a significant sign of the general civil and political status of a certain country. This idea was quoted from the following report: «Attaining, producing, creating and employing knowledge is a major tool in human development and renaissance. There is a three-faceted close relationship between development, freedom and knowledge. The way to strengthen the Arab knowledge performance is the key to reform the Arab development status» (Al Maktoum Foundation, 2009).

The right to know is considered the other side of the freedom of expression. The direct meaning of freedom of expression is related to "the right of people to express their opinions and ideas.» The 
ulterior meaning though, reflects the right of the receiver of those ideas to find ways for information flow away from government intervention or other types of intervention.

On the other hand, the right to know is the theoretical base of the freedom of mass media. The major function of the media practitioner resides in satisfying the audiencess right to know and ensuring the audiencess right in receiving important and genuine information (Saleh, 2002: 192).

Abiding by the renowned principle that all rights are undivided and inseparable, the right to know is not only an important right in itself, but also an instrument to activate the practice of other rights. Therefore, Arab countries are obligated to provide citizens with the right to access information in order to enjoy all other rights. Information access right boosts economic and social rights through three sequential phases that seem mostly absent in the Arab world. The first phase is related to citizen awareness (that results in creation and activation of their rights); followed by the second phase concerning achieving surveillance (based on the information access and its vital role in monitoring government performance and achievements regarding fulfilling its obligations). The last phase concentrates on the right of accountability (based on the concrete role of information to enhance suing rights in economic, social and cultural matters; thus boosting positive direct defense mechanisms in the community).

\section{The Right to Know in Arab and International} Charters

The U.N. admitted early enough the right to circulate information as a fundamental human right, through the resolution 59 adopted by the general assembly since holding its first meeting in 1946. The resolution clearly stated that information freedom is a fundamental human right and the criterion of all other freedoms adopted by the U.N.

Article 19 of the Universal Declaration of Human Rights is considered the premier fundamental law concerning the freedom of circulation of information (General Assembly, 1948). This article includes clauses related to freedom of expression and freedom of circulation of information in three major domains: the right to seek information, the right to receive information and the right to transfer information through publishing and broadcasting without being bound to a certain location. The three previous domains are not limited to the relationship between individuals and governmental entities, rather it is a general right insinuating that receiving and sending knowledge is an individual human right (Saleh, 2007:
325).

Article 19 of the International Covenant on Civil and Political Rights ratified the right to know and freedom of circulation of information similar to what happened with Article 19 of the Universal Declaration of Human Rights (UN General Assembly, 1966), concerning the unbound geographical domain. Nevertheless, the covenant bound the execution of this right by six restrictions: respecting the rights of others, respecting the reputation of others, protecting national security, protecting general system, protecting public health and finally protecting public morals.

Article 19 is criticized for repeating the same flaw that most Arab legalizations suffer from, and that is the unclear definitions of the restrictions and exceptions stated in the freedom of circulation of information concerning indefinite concepts as national security and public morals (Freedom of thought and expression foundation,2011:8).Moreover, international covenant on Economic and Social Rights (UN General Assembly, 1976) ensured the right of every individual to participate in the cultural arena and benefit from the scientific development and its practices. In 1993 the Bureau of the Special Rapporteur on Freedom of Opinion and Expression was established based on the resolution of the UN Commission on Human Rights. The bureau handled the mission of clarifying the real content of freedom of opinion and expression that was provided in multiple international codes. It stressed the freedom of circulation of information as a basic human right. In the bureau's report issued (1998), the freedom of opinion and expression were asserted to include freedom to acquire information. In 2000 the report ensured repeatedly that freedom of circulation of information is not only the main pillar of democracy, but also the main the basis of participation and development.

Following the past overview, it was obvious that the right to know is the "lost right in the Arab world" (Nasr, 2014). This article wasn't mentioned in the Arab Charter for Human Rights which was approved by the council of the Arab League in 15 September 1997; in contrast to what was mentioned in its preamble. The preamble of the Arab Charter for Human Rights stated clearly that the Charter was a reaffirmation of the principles of the United Nations Charter, the international Declaration of Human Rights and the provisions of the two international covenants of the United Nations regarding civil, political, economic, social and cultural rights.

The Reality behind the Principles of the Right to Know and Freedom of the Circulation of Information in the Arab World.

The right to know includes the right to acquire 
information related to state property, elections, political parties, candidates, natural resources, public spending, governmental salaries, public health and environment.

Article 19 Organization - a non-governmental organization established in London in 1987 to monitor surveillance - clarified a number of principles related to the right to know and freedom of circulation of information. The first principle is related to the "absolute disclosure of information" and is based on the rule stating that: every individual has the right to acquire information owned by governmental entities, unless the information is restricted. Actually this principle is not apparent in the Arab World, via legalization or practice. Citizens are obstructed from accessing information and governmental entities are granted absolute right not to reveal their information. The second principle is "obligation to publish» which means: not only should the governmental entities disclose information when asked, but they have to systematically publish certain administrative information. This obligation is not executed in the Arab World in the proper form. The third principle is to "promote the concept of open government", which means: governments are obligated to promote the culture of information disclosure. The current analysis reveals that the exact opposite is happening on regular basis. Arab governments are promoting the culture of secrecy and imposing it on governmental officials, through banning them from contacting mass media and through gag orders issued constantly.

The fourth principle tackles "limited exceptions». It deals with the fact that governmental entities must comply with all individual claims of revealing information; unless this information is considered exceptionally restricted. In the Arab world this principle is the mere opposite of the international principle. The Arab adopted rule is not complying with claims to acquire information and the exception is agreeing which happens in rare cases. The fifth principle tackles "procedures of information access facilitation». These procedures include all measures taken by the government to facilitate looking up information, assisting information seekers, assisting the illiterate and disabled ... etc. In the case of the Arab world, governments tend to put obstacles and obstructions in the way of the information seekers that would never facilitate information access, or let them practice this right as stated internationally.

\section{The Right to Know in Arab World Constitutions}

The constitutions of 60 countries in the world state the protection of the general right to access information. In an effort to execute these constitutional provisions, those countries enacted legalizations related to this human right. In contrast, other countries) constitutions state the protection of the right to know, nevertheless limit the knowledge to personal not public information, or certain types of information, or to journalists only, or recognize this right implicitly, or include it in the text related to freedom of expression, or in the text related to freedom of the press (Peled and Rabin, 2011). On the other hand, all Arab constitutions donst state the right to know explicitly with the only exception of the constitution of The Kingdom of Morocco issued in 2011. Article 27 of the Moroccan Constitution states - after ensuring the right of information access - that the access to information is specified by the law without being inconsistent with national defense, internal and external security and private life.

The researchers agree with the conclusion included in the Arab Organization for Constitutional Lawss Annual Book: 2015- 2016 issued by the Arab Organization for Constitutional Law in 2017. The new Arab constitutions or constitutional amendments issued after the Arab spring uprisings in a number of Arab countries as Morocco, Algeria, Tunisia, Libya, Egypt, Syria, Jordan and Yemen, still retain a large portion of the constitutional characteristics that existed before 2011. Although most new constitutions have added a number of rights, they have generally kept the same enforcement mechanisms, with some important exceptions (Al Aly et al., 2017: 9)

The Arab constitutions could presumably guarantee the right to freedom of expression "as regulated by the law." Such articles may seem neutral and in accordance with international law. Months later, however, the legislatures may issue a law under which social media statuses that "harm national unity" are prohibited. The increasingly politicized judiciary could then presumably interpret a nonviolent Facebook post that calls for peaceful protests in rejection of a presidential decree as "harming national unity;" the social media user in question is then arrested, interrogated, charged, and sentenced in a manner that certainly exists in compliance with the law, and possibly-arguably-in compliance with the vaguely constructed, vaguely worded constitution (El-Sadany, 2017: 5).

It is worth mentioning that any constitutional reform in the Arab world would be needed to keep up with global constitutions, digital and information age. The article should state the supremacy and major importance of the right to know, based on the fact that this right is the main pillar in establishing democracy. The crucial need of information will be indispensable to allow citizens to participate effectively in decision 
making and ensure accountability of officials; thus executing the right to know as a major component of freedom of expression and freedom of the press.

The Protective Laws of the Right to Know in the Arab World

The last decade of the twentieth century witnessed an unprecedented development in the world ss approach to legalize information freedom, especially with the fall of Berlin Wall and the massive growth of civil societies claim to access information on environment, governmental policies, public health, law drafts and corruption cases (Access Information Europe and the Network for Reporting, 2010). By 2012, 90 countries have already issued laws to protect the right to know, including China, India, Russia, Most of Europe, Central Asia, half of Latin America, 10 countries in Asia Pacific, 10 countries in Africa and two countries in the Middle East.

Nonetheless, the Arab world is considered the least region to encounter regulating the right to know and the right to information access. Only two Arab countries regulated this right - Jordan and Morocco - bearing into consideration that the Jordanian laws considering this issue is weak in light of the fact that the law fulfilled a governmental not a societal demand.

Reflections of the Right to Know on Freedom of Information and Freedom of the Press

The research in hand discusses the reflections of the right to know and the right of circulation of information on freedom of the press, through presenting 6 major Arab controversial issues. The issues discussed hereafter are presented in the following sequence: secrecy of information, public interest, gag orders, information classification, banning governmental employees from revealing information to the press, the right of media to attend public meetings and court hearings.

\section{Secrecy of Information and Public Interest}

Although human rights believe in the full right of journalists to access information sources, public interest requires in some incidents, imposing publishing bans on information that would compromise national, military, economic and social security. That is why governments: both third world and democratic prohibit access to certain types of information, only the difference resides in the degree of prohibition.

Arab governments impose a sort of ban on certain types of information prohibiting journalists from accessing them. In fact, the problem of imposing publishing bans on certain topics and events in Arab countries is rooted in the un-separation between matters of national security - as claimed by government - and the security of the government itself - in light of ensuring its safety and long ruling period - through hiding its defects.

\section{Gag orders (Publishing Bans)}

Presidents and prime ministers in all the world, including Arab countries preserve their right to issue administrative decisions related to blocking information and un-authorizing publishing or broadcasting if the information tends to be nationally sensitive from their point of view. In Arab countries as Egypt, the constitution and law defines clearly the type of information the president would have full right to gag, namely: military budget and armament agreements.

Nevertheless, practice unfolds that gags expand to include in prevalent cases various types of information related to: government performance, wealth of rulers, information that will endanger relations with neighbor countries and sectarian violence. In some cases, the president transfers this right to the Judiciary represented in the public prosecution that will issue gags and publishing bans either in sensitive or ongoing cases.

\section{Classification of Information}

In order to ban media from accessing certain kinds of information that should not be published or broadcasted, governments were keen to classify governmental documents based on their degree of secrecy. This fact is related to governmental decisions not to release official documents, unless a certain time span has elapsed. This time span is sometimes estimated to be 50 years from the time the document was issued and even longer. In this matter some researchers asserted that only $0.5 \%$ of the classified documents are indeed worth classifying.

Governments) misuse of their right to classify information caused lots of controversy over the years; especially the matter of limiting the right of the media to access sources of this so called classified information. Governments exaggerate even more, abuse and manipulate their right to classify information. They prioritize their interests and deliberately limit mediass right to access information. In this regard, Arab countries impose maximum restrictions on the media during their search of important information and governmental documents; to the extent of issuing legislative binding clauses to preserve document secrecy and national security and 
defense information.

Article 26 of the Omani Press and Publications Law issued by the Royal Decree number 49 in 1984 does not permit publishing any information that could endanger the safety of the Sultanate and its internal and external security. The same article does not permit publishing all military news and official confidential communication unless authorized by the designated authority. In Lebanon, Article 12 of the Lebanese Press and Publications Law modified by article 330 in 1994 bans publishing news of ongoing criminal and felony investigations before publicly announcing them in official trials. The same applies to proceedings of cabinet meetings and secret parliamentary meetings. In Syria, the law bans publishing news on criminal and felony charges before publicly announcing them in official trials. The same applies to all news related to military safety, movements, numbers and equipment unless the information is issued by the ministry of defense for publishing purposes. The Egyptian Article 189 in the penal code prohibits publishing proceeding of secret court hearings whether civil or criminal.

Banning Governmental Employees from Revealing Information to the Press

Since long ago, it was known that the majority of governmental corruption cases were unveiled by the press as a result of a tip through an employee leak. Employees are encouraged by the guarantees stated in the press laws of some countries concerning protecting information sources and ensuring the right of the journalist not to reveal his source.

In the context of imposing secrecy on governmental affairs and denying the press the chance to criticize their performance, Arab governments reside to legal and illegal measures to prohibit governmental employees) contact with the press. In some entities, a spokesperson or a public relations officer is assigned to communicate with the media. In other entities, employees should acquire an official permit to talk to the media. Other sovereign Arab authorities require new employees to sign a confidentiality agreement when hired to guarantee their disengagement from media contact. Military and police institutions are ideal examples of such practices.

Moreover, some of these sovereign authorities extend those confidentiality agreements to biographies written by their employees even after pension; claiming they might include confidential information on their activities when they were in office. A classic example was the jail sentence of Egyptian War Marshal Saadin Al Shazli - Chief of Army War Staff during October 1973 War. He was sentenced for publishing military confidential secrets in his biography issued in a book in 1995.
The Right of the Media to Attend Public Meetings Most countries in the modern world allow journalists to attend parliamentary sessions and court hearings, whilst denying them the right to attend cabinet meetings. Instead, a spokesperson briefs journalists on crucial developments. The right to attend parliamentary meetings is considered one of the earliest genuine rights acquired by the press since its early inauguration in the world.

Arab parliaments likewise, allow newspapers to attend their sessions and publish the content of their discussions through issuing permits to newspaper representatives. This regulation however, is utilized occasionally to discriminate pro- government newspapers from opponents that are not allowed to attend the sessions. This practice was first executed in Egypt since 1924 when representatives of opponent newspapers were banned from attending parliamentary sessions for criticizing cabinet performance. Moreover, live streaming from the sessions has always been banned. Instead, audiovisual reports with scenes from the sessions are prepared, censored and broadcasted as news info. After the Egyptian uprising in 2011, a major broadcasting shift took place regarding inaugurating a new channel on national television designated to airing parliamentary sessions only.

\section{The Right of Media to Attend Court Hearings}

Laws of press and publications in Arab countries assert on the right of the various press and media channels to attend court hearings and publish details of their proceedings. At the same time, legislation emphasizes that media must respect judges> decisions and public prosecutors in case the investigation or the trial is decided to be confidential. However Arab legislations, executed through the laws of publishing or penal codes or special laws, restricted publishing trial news or judicial proceedings. These measures are taken inspite of the right of the public opinion to know how justice is being carried out, how fair the trials are and the execution of legitimacy and the prevalence of law. Egyptian law as an example allows journalists to attend ordinary court hearings and publish their proceedings on condition that their articles would not precede court rulings or comment on the verdicts. The law also bans clearly publishing names or photos of the defendants unless being sentenced. If the defendant is a juvenile (under 18) names and photos are prohibited completely. The Jordanian Press and Publication Law - issued 1993 - adopted the right of the journalist to acquire information from its sources. Nevertheless, the law also granted courts the right of holding confidential trial sessions to protect 
national security, fight crime or achieve justice. Similarly, Article 29 of the Omani Publishing law states: «Publishing investigation proceedings or court hearings concerning personal matters and others is prohibited as decided by court.»

\section{The Right to Know in the Arab World in the Digital Age}

The use of digital media depending on the internet has witnessed rapid growth in the Arab world since it was introduced by Tunisia, as the first Arab country to connect to the internet in 1991. The 2017 estimates, indicate that the number of internet users in the Arab world reached 185 million users, representing about $44 \%$ of the population of Arab countries; that is 421 million accounting for $4.8 \%$ of the world ss population. Egypt scores top notch concerning the number of internet users by about 40 million, followed by Saudi Arabia by 21 million, Morocco 20 million, Algeria 18.5 million, and Iraq 14 million.

The use of digital technologies has provided a new and effective outlet for Arab opposition parties and groups; many of which have enabled them to reach out to the masses, and gain sympathy and support of more citizens both at home and abroad. This process has been going on without the parties and groups being subjected to the constraints of traditional media.

In addition to the collective freedoms offered by the digital age to opposition groups in the Arab world, it has also entrenched new individual freedoms. It has provided the Arab citizen with real opportunities for free expression of opinion and information seeking. The digital age created freedoms in the Arab world that were not widely available before; especially in light of the limited freedom of expression in the traditional media owned by the ruling elites or intellectuals close to those elites; and the continued restrictions on the right to know, freedom of expression and assembly.

Indeed, the new freedoms established by the digital age are facing a wave of criticism that amounts to moral terror, in addition to severe punitive measures. The communication potential provided by contemporary technologies is perceived as a threat to the political elites, who feel they are being attacked by this continuous and unending information flow. When new media help people extend the limits of their freedoms, anxiety replaces doubt. The authorities, immediately control this new medium and begin to take action to control words and images and control the new threat they pose.

As with traditional media, the Arab governments hastily blocked the new means that might cause them some problems due to the space of freedom they provide which is far from their control. Governments resorted to all censorship methods they have used with traditional media, as well as electronic censorship through the wide use of electronic filtering programs, that enable internet control from the source itself. Moreover, some countries have resorted to monopolizing the service, as well as using the common traditional solution of fabricating cases and imprisoning those who exceed the red lines with such allegations as «abusing the reputation of the state, defamation, protecting public morals and values ... etc.»

In general, the digital media offer an almost identical stance to that of post-print and newspapers spread in the Arab world in the mid-nineteenth century. In many Arab countries, the trends of contemporary Arab political elites appear to be similar to those of their historical counterparts; especially in the development and implementation of oppressive laws and measures against these new media. What is new in this matter, is that the new media themselves are introducing new ways of restraint and prevention that did not exist in the past. New media brought with them new ways to limit the right to know and freedom of expression. For the first time in history, means of restraint have become technological and embedded within the media themselves.

Many Arab countries use filtering technology to limit the flow of information on the internet. For example, Gulf States governments such as Saudi Arabia, Bahrain, Yemen, the United Arab Emirates and Oman use a classification and filtering program that acts as an intermediary between the internet service provider (a government-controlled telecommunications company) and the end-user. This program filters internet content and blocks access to unwanted sites and materials whether political or sexual (Human Rights watch, 1). Internet censorship is not only confined to technological surveillance, but also varying degrees of the traditional forms of censorship of traditional media are applied. Legal control methods are utilized to dominate internet content. Some Governments apply existing laws on traditional media to digital communication technologies. In contrast, a number of other governments have issued special internet laws to monitor internet content (Global Internet Liberty Campaign, 10-11).

The Arab countries are unique in this regard concerning two matters. The first is the monopoly of governments on providing internet services, which makes it easier for them to control surveillance. This phenomenon is almost unique to the Arab countries and stems mainly from the Arab experience with the traditional media that established the rule of government control over 
all - or at least the majority of expression outlets in society. It is natural, in the light of this experience that the internet will not deviate from this rule. The second is the link that Arab governments are trying to establish between censorship and what they see as a specific cultural milieu that requires «the preservation of ethical values.» However, the reality of internet censorship in the Arab countries confirms that censorship, blocking websites and chasing online publishers and bloggers are for more political than ethical reasons.

What distinguishes Arab interaction with the techniques of the digital communication age is the attempt of Arab governments to justify their failure to guarantee the right to know and freedom of expression and impose strict technological control and all other forms of censorship on the internet; under the allegation of "preserving of ethical values.» These allegations resemble to a great extent allegations regarding «preserving public order, social peace and national security, " raised by the Arab governments in the face of activists demands for the right to know, freedom of expression and freedom of the press.

\section{Conclusion and Recommendations:}

The current study concludes that the right to know and all other related rights concerning the freedom of the press are nonexistent in the Arab World. The Arab reality suffers from multiple contradictions mainly: not abiding by the articles of the universal declaration of human rights, the international covenant on civil and political rights and international covenants of human rights regarding: freedom of expression, freedom of the press and freedom of circulation of information. This deficiency comes despite the fact that lots of Arab countries signed these international covenants. Let alone the apparent contradictions between what the Arab constitutions stipulate on ensuring freedom of opinion and expression and what the laws of publishing and press state in Arab countries.

Despite the new freedoms established and ensured by the digital age in the Arab World, digital and new media as platforms of free expression of ideas and thoughts are surrounded by massive technological and technical restrictions. Online publishing in the Arab World is censored and most apparent in this case is: the technological surveillance via classification and filtering software, violent police surveillance leading online activists to trials, jail and physical abuse.

In light of the prior findings, the study recommends:

1- The necessity of Arab world recognition of the right to know and introducing articles in its constitutions to execute that end.

2- Issuing laws and legislations to regulate the right to know and clarify its boundaries and practice.

3- Promoting the right to know through NGOs and human rights societies established in the Arab World; in matters related to the unconditional access of journalists to information sources, public meetings and court hearings.

4- Reconsidering active laws of publishing and press in the Arab World, thus enhancing the journalists) rights to access human, governmental and archive sources unrestricted.

5- Limiting the phenomenon of publishing bans and gags that denies Arab societies from acquiring information in various cases related to the welfare of these societies themselves.

6- Establishing fair systems of information classification and ensuring lifting secrecy measures from all governmental activities.

\section{References:}

Abd Al Gawad, A. A. (2003). The right of people to know (In Arabic). Najah University for Human Sciences Journal, 17(2), 419- 442.

Access Information Europe and the Network for Reporting on Eastern Europe. (2010). Legal Leaks Toolkit: A Guide for Journalists on How to Access Government Information.

Access To Information: an instrumental right for empowerment. (July 2007). Article 19.

Al Aly, Z. et al. (2017). Arab Organization for Constitutional Law Annual Report: 20152016- (In Arabic). Tunisia: Arab Organization for Constitutional Law.

Al Araby, O. (2002). The internet: Uses and spread in Saudi Arabia (In Arabic). Paper submitted to Communication Revolution and Gulf Societies Conference, Sultan Qaboos University, Muscat.

Al Laban, S.D. (2002). Freedom of expression and censorship on New Media (In Arabic). Paper submitted to Communication Revolution and Gulf Societies Conference, Sultan Qaboos University, Muscat.

Al Nashmi, E. et al. (2010). Internet political discussions in the Arab world: A look at online forums from Kuwait, Saudi Arabia, Egypt and Jordan. The International Communication Gazette. 72(8), 719738. DOI: $10.11771748048510380810 /$

Al-Jenaibi, B. (2016). The Twitter revolution in the Gulf 
countries. Journal of Creative Communication, 11(1), 6183-. DOI: 10.11770973258616630217/

Ang, P. H. (1999). How countries are regulating internet content. Singapore: Nanyang Technological University.

Boserup, L. K. (2005). An introduction to openness and access to information. Copenhagen.

Bukhart, G.E. (1998). National security and the internet in the Persian Gulf region. Available online at: http://www.georgtown.edu/research/pgi98.8.html

Chalaby, J. K. (2000). New media, new freedoms, news threats. Gazette. 26(1), 23- 29

Ellickson, R. C. (1991). Order without law: How neighbors settle disputes. Cambridge: Harvard University Press.

El-Sadany, M. (2017). Human rights in the constitution: A survey of the Arab uprisings. Paper Presented to Tahrir Institute for Middle East Policy and Arab Center. Washington DC.

Fadl Allah, O. S. November (2012). A knowledge society between the right to access information and the challenges of reality and hope (In Arabic). Proceedings of the 23rd Conference of the Arab Union for Libraries and Information entitled: (Government, Society and Integration in Building Arab Knowledge Societies). Ministry of Culture, Arts and Heritage, Qatar and the Arab Federation of Libraries and Information, Doha.

Freedom of Thought and Expression Foundation. (2011). Freedom of circulation of information: A comparative law study (In Arabic). Cairo.

Global Internet Liberty Campaign. Regardless of frontiers. Available online at http://www.gilc.org/ speech/report/

Halstuk, M. E. and Chamberlin, B. F. (2001). Open government in the digital age: The legislative history of how Congress established a right of public access to electronic information held by Federal Agency. Journalism and Mass Communication Quarterly. 78(1), 45- 64.

Human Rights Watch. The Internet in the Mideast and North Africa: Free expression and censorship. Available online at http://www.hrw.org/hrw/ advocacy/internet/mena.
Jagwanth, S. (2002). The Right to Information as a Leverage Right. In Calland, R. and Tilley, A., eds. The right to know, the right to live: Access to information and socio-economic justice. Open Democracy Advice Centre.

Mohammed Bin Rashed Al Maktoum Foundation. (2009). Arab knowledge report 2009: Towards productive intercommunication for knowledge. Dubai. UAE.

Nasr, H. (2003). Internet and media: Electronic journalism (In Arabic). Kuwait: Al Falah Publishing.

Nasr, H. January 27th (2014). The right to know between international codes and national laws. AlShabiba.

Peled, R. and Rabin, Y. Winter (2011). The constitutional right to information, Columbia Human Rights Law Review. 42(2), 375- 378.

Pettrachin, A. (2018). Towards a universal declaration on internet rights and freedoms? The International Communication Gazette, 80(4), 337- 353. DOI: 10.11771748048518757139/

Rathmell, A. (1997). Netwar in the Gulf. Janes's Intelligence Review. 3. Available Online at: http:// www.infowar.com/class_3/class39-.html_ssi

Report of the Special Rapporteur. 18 January (2000). Promotion and protection of the right to freedom of opinion and expression. UN Doc. E/CN.463/2000/. Para. 42

Report of the Special Rapporteur. 28 January (1998). Promotion and Protection of the Right to Freedom of Opinion and Expression. UN Doc. E/CN.440/1998/, Para. 14.

Saleh, S. (2002). Media ethics (In Arabic). Kuwait: Al Falah Publishing.

Saleh, S. (2007). Communication revolution and media freedom (In Arabic). Kuwait: Al Falah Publishing.

Shuji, H. (1997). The internet and Middle East Studies. Japanese Institute of Middle Eastern Economic Review. Available online at: http://www.pws.prserv. net/h.

UN General Assembly Resolution 217000. December 10th, 1948. 
UN General Assembly Resolution. December 16th, 1966, executed in: January 3rd, 1976.

UN General Assembly Resolution. December 16th, 1966.

UN General Assembly. 1946 Resolution 59 (1). 65th Plenary Meeting, December 14. 